\title{
Reduction of the number of faults caused by lightning for transmission line
}

\author{
Dinh Chung Phan \\ Faculty of Electrical Engineering, The University of Danang-University of Science and Technology, Vietnam
}

\begin{tabular}{l}
\hline \hline Article Info \\
\hline Article history: \\
Received Jan 28, 2019 \\
Revised Apr 3, 2019 \\
Accepted Apr 4, 2019 \\
\hline
\end{tabular}

\section{Keywords:}

Increase in insulator string length

Lightning caused fault number

Lightning tripping rate

Line improved algorithm

Surge arrester installation

\section{Corresponding Author:}

Dinh Chung Phan,

Faculty of Electrical Engineering,

The University ò Danang-University of Science and Technology,

54 Nguyen Luong Bang Road, Danang city, Vietnam.

Email: pdchung@dut.udn.vn

\begin{abstract}
In this paper, author considers three schemes to reduce the fault number caused by lightning on transmission lines. Three schemes considered in this research include increase in the insulator string length, surge arrester installation, and surge arrester installation in combination with increase in the insulator string length. A new algorithm is proposed to determine the best scheme which guarantees the number of faults caused by lightning satisfies the required value and its investment is the cheapest in them. With a foregiven required value of the fault number caused by lightning, this algorithm indicates the number of tower positions needing to improve and improving methods at those towers in detail. To verify this algorithm, a sample $220 \mathrm{kV}$ transmission line is used. With this transmission line and the desired value of fault number caused by lightning, the algorithm gives the lowest investment cost and it also demonstrated in detail which towers should install surge arrester, which towers should increase the insulator string length.
\end{abstract}

Copyright (C) 2019 Institute of Advanced Engineering and Science. All rights reserved.

\section{INTRODUCTION}

Overhead transmission line is often several tens of meters in height [1] and from several kilometers to hundreds of kilometers in length [2]. Therefore, the route of transmission lines can cross areas with different natural conditions. Hence, the parameters of a real transmission line's towers including the heigh of tower, length span, tower footing resistance, and so on are not constant. In operation, lightning can strike to nearby the line route or directly to the line. In both two cases, the external overvoltage phenomenon occurs on the line's insulator [3-5]. It depends on the lightning current amplitude, this overvoltage can be over the withstand voltage of the insulator string and hence, the spark discharge occurs on the insulator. If the transition from the spark to arc discharge is successful, a short circuit will occur and then, the line's circuit breaker will trip to isolate this lightning caused fault [5]. It means the transmission line is unscheduled supply interruption [4].

If lightning directly strikes to the phase wire of line, the probability of the fault occurrence is very high. To reduce the risk of lightning to transmission line, shield wires are often hanged on the top of the line $[1,5]$. With the transmission line hanged shield wires, the lightning mainly strikes to the shield wires and hence, the number of shielding failures reduces insignificantly if the shield wires' protective angle is small enough. Though the shield wires are grounded at all towers, the over-voltage on the insulator string of the line still occurs when the lightning strikes directly to the shield wires $[3,5]$ and hence, it can cause unscheduled supply interruption. Many publications introduced the calculation method of the lightning tripping rate (LTR) for the transmission line [6-11]. 
With a transmission line hanged shield wires, reducing LTR is still an interesting issue. Conventional methods to reduce LTR include decrease in the shield wires' protective angle, the tower footing resistance at towers and increase in the insulator string length. Recently, surge arresters (SA) are implemented on the line to reduce LTR. Some studies used Electromagnetic Transient Program (EMTP) software to analyze the impact of lightning strike on the line [12-18] and to evaluate the impact of surge arrester and tower footing resistance [14-16] on the lightning performance. In fact, to reduce LTR of a transmission line, the SA installation at all towers of a line is almost impossible because of high cost of SA.

An interested problem is that we must reduce the LTR of transmission line to a desired value but we must save investment cost as much as possible. It means that we can not improve all towers of line. We need to determine tower positions and improving method to obtain the highest efficiency. Practically, the number of faults caused by lightning (NFCL) per year at each tower depends on many parameters such as tower's height, span length, ground resistance, etc. Therefore, to reduce the LTR value with a cheap investment cost, we should find towers with high NFCL value and then, we must propose reasonable improving methods for those towers. Currently, it is hardly a publication to solve this problem.

In this paper, author proposed an algorithm to solve that problem. This algorithm will determine a suitable scheme to reduce the number of faults caused by lightning (NFCL) on a transmission line to a desired value. This algorithm is developed based on three methods including increase in the insulator string length (ISL) method, SA installation method, and the combination of SA installation with ISL. The scheme determined by this algorithm must guarantee that the total NFCL or LTR value satisfies the required value and saving the investment cost. To verify this algorithm, we implement in to a $220 \mathrm{kV}$ transmission line. The results will be evaluated and analized.

\section{PROBLEM OF METHODS OF LIGHTNING TRIPPING RATE REDUCTION}

There are many methods to reduce LTR or NFCL of a transmission line. Conventional methods include shelding wire, decrease in tower footing resistance, increase in the insulator string length, surge arrester installation, etc. In almost transmission lines, shield wires have already been hang on the top of the line and the tower footing resistance is quite small but the LTR value is still quite high. Hence, it is still required to reduce LTR to a desired value. In this case, the methods of surge arrester installation and increase in the insulator string length should be considered. These methods have both benefit and drawback as following:

\subsection{Surge arrester installation}

SA is conventionally used to protect equipment in power substations from external overvoltages traveling from the connected transmission line. However, recently, it is used to protect an insulator string instead of horn gap because it can extinguish automatically arc. Therefore, when we hang a suitable SA in parallel the insulator string, the flashover does not occur on the insulator string in the case of lightning strike. It means if we hang SA at all insulator strings of a tower, the NFCL value at this tower can be supposed zero. It is worth to note that SA is too expensive to install at all towers of a transmission line.

\subsection{Increase in the insulator string length (ISL)}

The length of the insulator string impacts significantly on the NFCL value. The main reason is that the normal electric field $E_{\text {norm }}$ is inversely proportion to the insulator string length $l_{\text {ins }}$ and hence, it leads to decrease in the arc discharge probability $\eta$, as (1)-(2) [12].

$$
\begin{aligned}
& E_{\text {norm }}=\frac{U_{r}}{l_{\text {ins } \sqrt{3}}}, \\
& \eta=f\left(E_{\text {norm }}\right),
\end{aligned}
$$

where, $U_{r}$ is the rated voltage on insulator string $[\mathrm{kV}]$ in normal operation. Moreover, as the insulator string length $l_{\text {ins }}$ is increased the insulator string's basic lightning impulse insulation level $(B I L)$ also increases as (3) $[13]$.

$$
B I L=\left(a+\frac{b}{t^{c}}\right) l_{\text {ins }}
$$

where $a, b, c$ are constants. As a result, when we increase the insulation length $l_{\text {ins }}$, the occurrence probability of fault caused by lightning is reduced. 
However, with an existing transmission line, the increase in the insulator string length brings some drawbacks. Firstly, it reduces the air gap between the phase wire and exposed conductive part. Secondly, the overvoltage wave travelling to the terminal power substations will increase and hence, it causes a great damage to equipment. Therefore, the increase in the insulator string length should be limited. Normally, the number of porcelain in $110 \mathrm{kV}$ and $220 \mathrm{kV}$ is normally limited in 9 units and 16 units. It is also noted that the increase in an insulator string length by adding porcelain units is more saving than a SA installation.

In summary, the SA installation is very good in technical terms but it is very exspensive while the increase in the insulator length is quite cheap but it has a negative impact on technical terms. Therefore, we need to determine a scheme to improve the line's towers so that the line's LTR satisfies the requirement and we can save the investment cost.

\section{ALGORITM PROPOSAL TO DETERMINE THE BEST IMPROVING SCHEME}

The objective of this section is to propose an algorithm to determine the best improving scheme for a transmission line such that the line's LTR or NFCL in total meets the desired value and this scheme's investment is the cheapest. Here, we propose the algorithm as shown in Figure 1(a). This algorithm is developed up on the NFCL value at each tower. Therefore, we need to calculate the NFCL value at each tower on the transmission line to obtain array PN which contains the NFCL value of all towers. Hence, the total NFCL of the line, $n_{0}$, is calculated by (4)

$$
n_{0}=\operatorname{sum}(P N)
$$

If the current value, $n_{0}$, is over the required value $n_{r e q}$, we need to determine an improving method so that $n_{0} \leq n_{\text {req }}$. In here, we consider three improvement methods. The first one is solely increase in the insulator string length (ISL). The second is solely SA installation. The last method is the combination of SA and ISL. The designated scheme by the algorithm is the best method which ensures the lowest cost and NFCL value meeting the requirement. The detail description of the above methods is following.

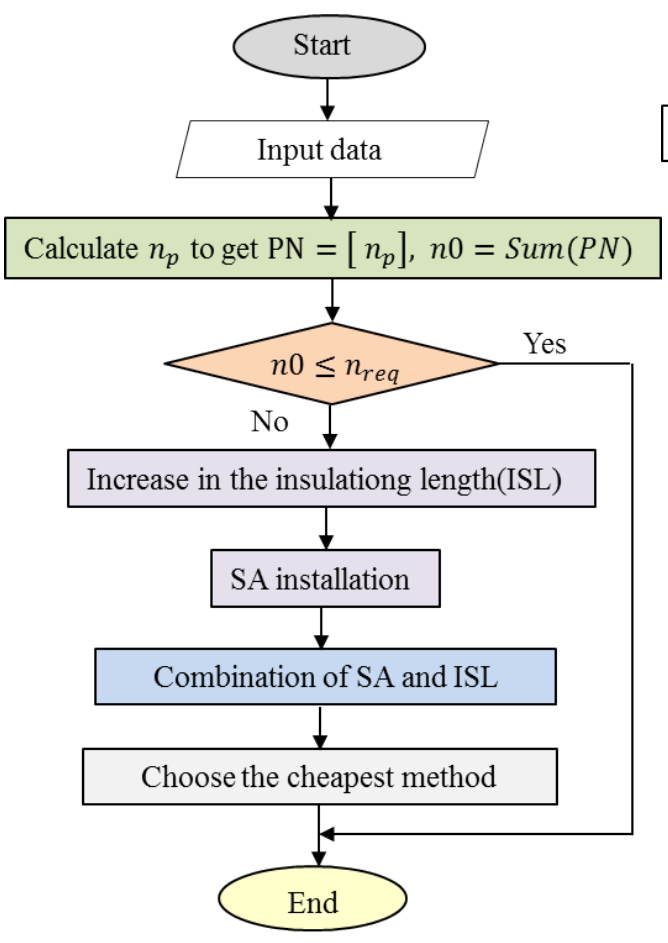

(a)

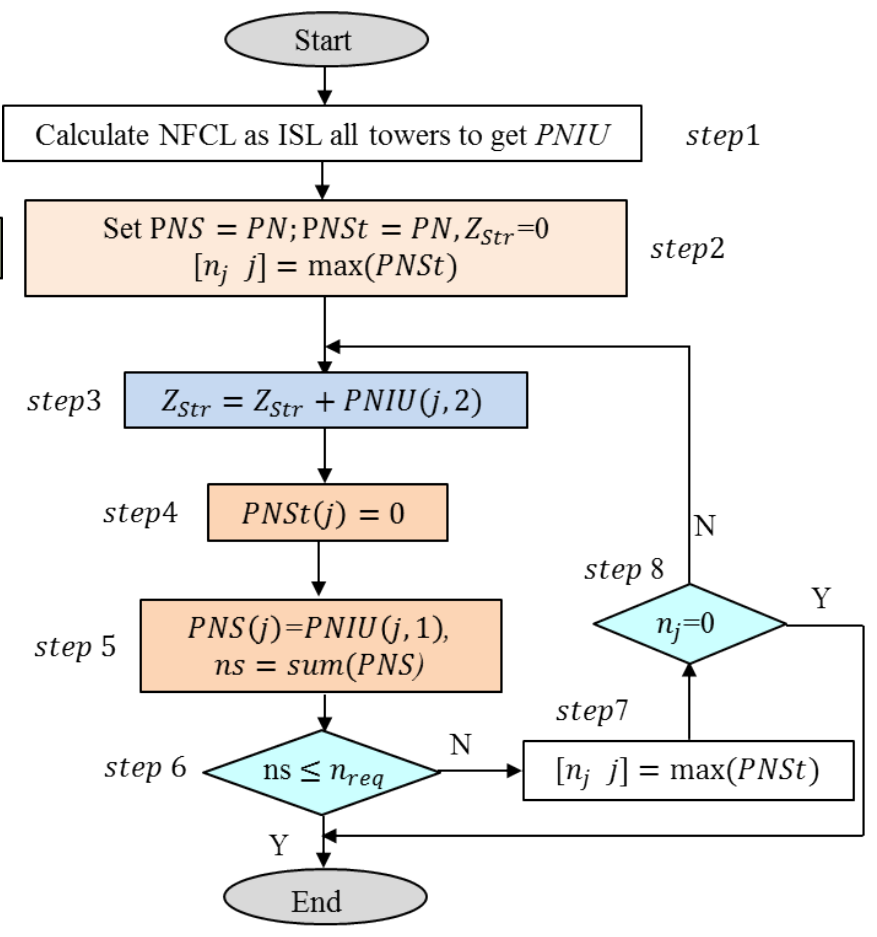

(b)

Figure 1. Algorithm to deternine the proposed method: (a) General algorithm, (b) ISL algorithm 


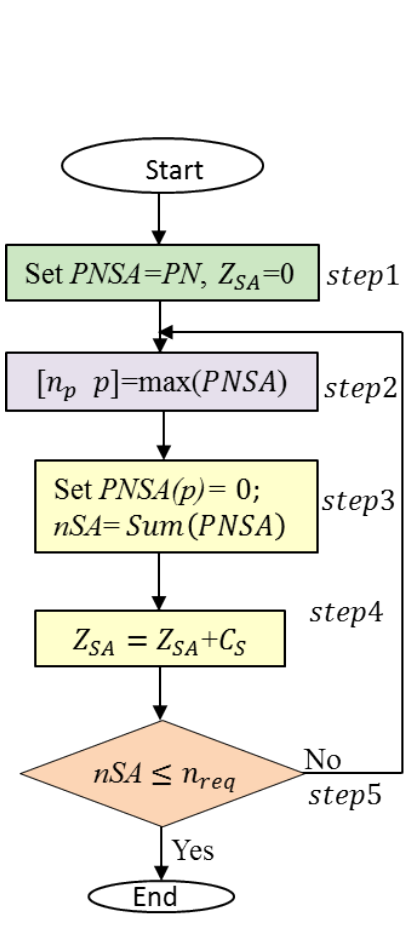

(c)

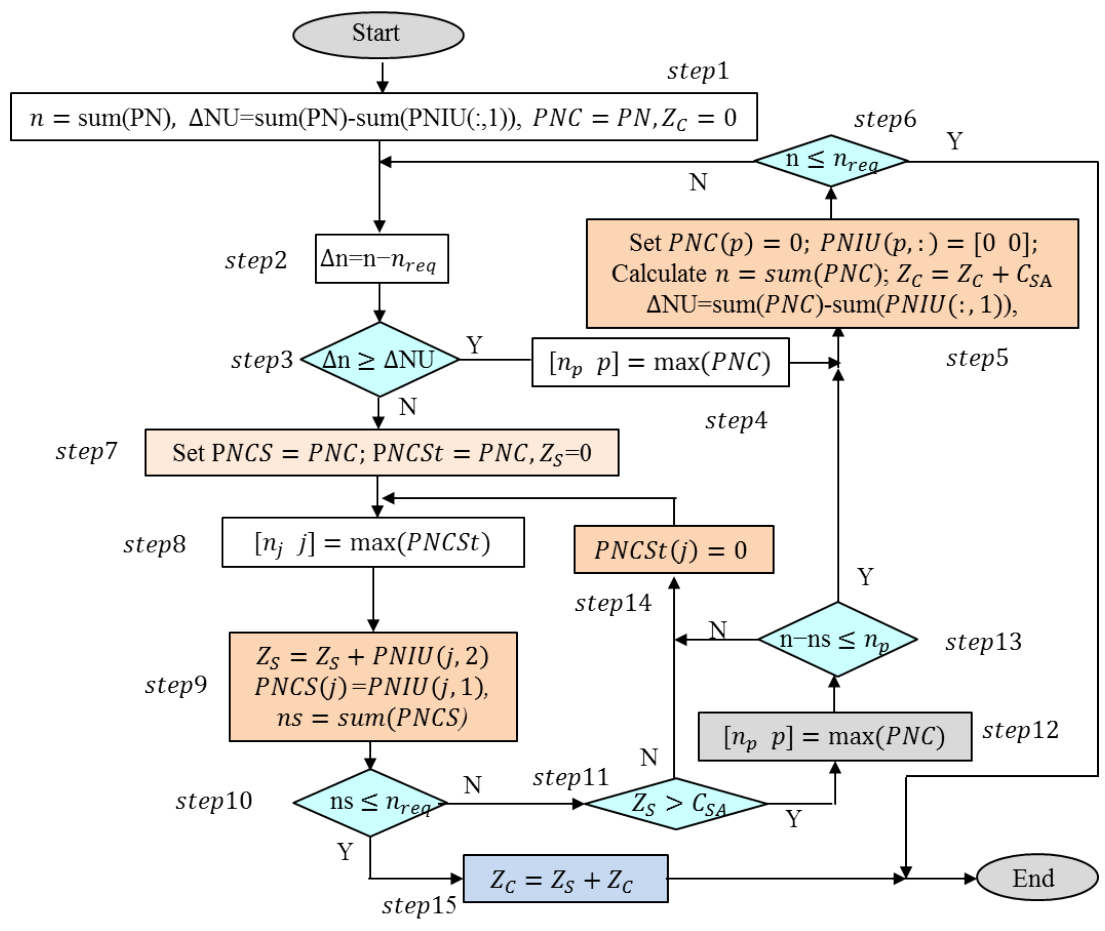

(d)

Figure 1. Algorithm to deternine the proposed method: (c) SA installation algorithm,

(d) Algorithm of the combination of SA and ISL

\subsection{The algorithm of increase in the insulator string length (ISL)}

The main principle of the ISL method algorithm is

a. Porcelain units is prioritized to add to the insulator string of tower with the highest NFCL value;

b. Towers whose distance to the nearby power substations is below $3 \mathrm{~km}$ should not increase the insulator string length;

c. Towers far from the substation between 3 and $4 \mathrm{~km}$ only allow adding a porcelain unit; and other towers, we can add two porcelain units;

d. Adding porcelain units should be carried out all phases. following.

With above principle, the ISL algorithm includes 9 steps as shown in Figure $1 \mathrm{~b}$ and is described as

Step 1: Calculate NFCL value at each tower corresponding to the maximum porcelain units according to the above princible. We obtain a matrix PNIU whose first column is new NFCL values and its second column is the price to add porcelain units. It is next to Step 2.

Step 2: Use an array PNS to contain the initial NFCL value at all towers, a temporary array PNSt to avoid fulfilling ISL again in next loops, and $Z_{S t r}$ to represent the investment cost of the ISL method. Here, we set $P N S=P N, P N S t=P N, Z_{S t r}=0$. We find the tower position having the highest NFCL value and not yet been added porcelain units to carry out ISL. We suppose that the $j^{\text {th }}$ tower is tower which satisfies the above conditions. We go to Step 3.

Step 3: Calculate the porcelain adding investment cost by adding $P N I U(j, 2)$ into $Z_{S t r}$. We go to Step 4.

Step 4: Set $P N S t(j)=0$ to avoid repeating this tower in next loops. We go to step 5 .

Step 5: Replace the $j^{\text {th }}$ tower's NFCL value by data corresponding to increase in the string length, $P N S(j)=$ $\operatorname{PNIU}(j, 1)$, and calculate the current NFCL in total, $n s$. We go to Step 6.

Step 6: Compare $n s$ to $n_{r e q}$. If $n s \leq n_{\text {req }}$, it is completed. Otherwise, it goes to Step 7 .

Step 7: Find the $j^{\text {th }}$ tower position where has the highest NFCL value, $n_{j}$. We go to Step 8 .

Step 8: If all towers is carried out ISL, it means $n_{j}=0$, the algorithm is completed. Otherwise, it returns Step 3. 


\subsection{Algorithm of SA installation}

As above mentioned, installing SA in parallel the insulator strings at a tower makes the NFCL value at this tower becomes approximate to zero. Hence, it is priority to install SA at the tower which has the highest NFCL value. The SA installation algorithm, as Figure 1c, is described as following.

Step 1: Use a new array PNSA to contain the NFCL value at all towers on the line. Initially, we set $P N S A=$ $P N$ and the investment of this scheme $Z_{S A}=0$.

Step 2: Find the $p^{\text {th }}$ tower with the highest NFCL value, $n_{p},\left(n_{p}=\max (P N S A)\right)$.

Step 3: Install SA at the $p^{\text {th }}$ tower. It means we set $P N S A(p)=0$.

Step 4: Calculate the investment cost by adding the SA installation price, $C_{S A}$, in to $Z_{S}$. It means $Z_{S}=Z_{S}+$ $C_{S A}$.

Step 5: Calculate the total NFCL value after installing SA at the $p^{\text {th }}$ tower, $n S A=\operatorname{Sum}(P N S A)$, if $n S A \leq$ $n_{r e q}$, we continue to find and install SA at another tower by returning to Step 2. Otherwise, it is finished.

\subsection{Algorithm of combination of $\mathrm{SA}$ installation and increase in the insulator length}

Comparing to a SA, the price of porcelain unit is much cheaper, but ISL at a tower makes the NFCL value reduce insignificantly. Therefore, we need to increase in the insulator string length at many towers. It is noted that

a. Principle of ISL is mentioned in subsection 3.1,

b. At one tower, it is not allowed adding both SA and porcelain units,

c. At one tower, either SA or ISL is carried out at all phases.

To develop the algorithm of the combination of SA and ISL, we use array PNC and array PNCS is to store the NFCL value of all towers when we combine SA installation and ISL, a temporary array PNCSt is used to avoid adding porcelain again at a tower. We use $Z_{S t r}$ and $Z_{C}$ to represent the investment cost for adding porcelain and whole scheme, respectively. The algorithm of combination method, Figure $1 \mathrm{~d}$, is described as following.

Step 1: Set $P N C=P N, Z_{C}$, and calculate the current NFCL in total $n=\operatorname{sum}(P N)$. We use $\Delta N U$ to evaluate the maximum of reduced NFCL value by ISL, with $\Delta N U=\operatorname{sum}(P N)-\operatorname{sum}(P N I U(:, 1))$. PNIU is obtain in the ISL algorithm. We go to step 2.

Step 2: Calculate the difference between $n$ and the required NFCL, $n_{\text {req. }}$. It goes to Step 3 .

Step 3: Check the condition of SA installation. If ISL cannot make the fault number, $n$, reduce to $n_{\text {req }}(\Delta n \geq$ $\Delta N U$ ), we go to Step 4 to install SA. Otherwise, we start fulfilling ISL by going to Step 7.

Step 4: Find a tower position to install SA. The $p^{\text {th }}$ tower with the highest NFCL is tower needing SA installation. We go to step 5 .

Step 5: Set the $p^{\text {th }}$ tower's NFCL at zero in both $P N C$ and $P N I U$. We set again $n=\operatorname{sum}(P N C)$, calculate again $\Delta N U$, and add the $\mathrm{SA}$ installation cost into $Z_{C}$ after installing SA at the $p^{\text {th }}$ tower. Then, we return to Step 6.

Step 6: If $n \geq n_{\text {req }}$, we need to return step 2. Otherwise, the algorithm is finished.

Step 7: From this step, we start carrying out ISL. We use a array PNCS to contain the NFCL value after adding porcelain units and a temporary array PNCSt to avoid adding units again in next loops, and $Z_{S}$ to represent the units adding cost. Here, we set $P N C S=P N C, P N C S t=P N C, Z_{S}=0$. Step 8 will be carried out.

Step 8: Find the tower position to add porcelain units. This tower must have the highest NFCL and has not yet neigther added porcelain units nor installed SA. We suppose the $j^{\text {th }}$ tower satisfies this condition. We go to Step 9.

Step 9: Calculate $Z_{S}$ by adding $P N I U(j, 2)$ in to $Z_{S}$ and set $P N C S(j)=P N I U(j, 1)$. Here, we use ns to represent the current NFCL in total of the line after carrying ISL at the $j^{\text {th }}$ tower. We go to Step 10.

Step 10: If $n \leq n_{\text {req }}$, Step 15 is fulfilled. Otherwise, it goes to Step 11.

Step 11: Compare $Z_{S}$ and $C_{S A}$. If $Z_{S}>C_{S A}$, we go to Step 12. Otherwise, we go to Step 14.

Step 12: Find the tower with the highest NFCL value. We supposed that it is the $p^{\text {th }}$ tower. We go to Step 13.

Step 13: Compare the efficiency of ISL and installing SA. If $n-n s \leq n_{p}$, we should install SA at the $p^{\text {th }}$ tower instead of ISL at many towers. Hence, we return to Step 5. Otherwise, we go to Step 14.

Step 14: Set the $j^{\text {th }}$ tower's NFCL in PNCSt at zerro. We return Step 8.

Step 15: Calculate the total investment of SA installation and ISL. The algorithm is finished. 


\section{VERIFICATION OF PROPOSED ALGORITHM}

The main objective of this section is to test the proposed algorithm. To verify the proposed algorithm, author applies this algorithm to a double circuit $220 \mathrm{kV}$ transmission line consisting of 115 towers. Some parameters of this line are given in Figure 2. This line crosses two areas with different natural conditions, the lightning flash number (LFN) of the first area (from $1-70^{\text {th }}$ tower) is $8.2 \mathrm{flashes} / \mathrm{km}^{2} / \mathrm{year}$ while the data of the second area (from $85^{\text {th }}$-the end tower) is 5.7 flashes $/ \mathrm{km}^{2} /$ year. We suppose that LFN of the line segment between two areas is interpolated linearly.

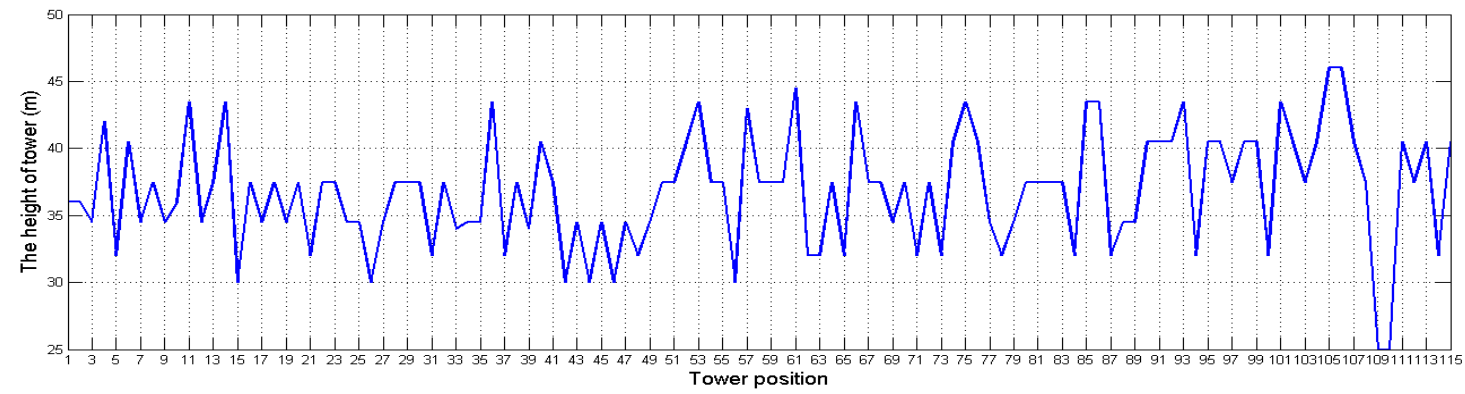

(a)

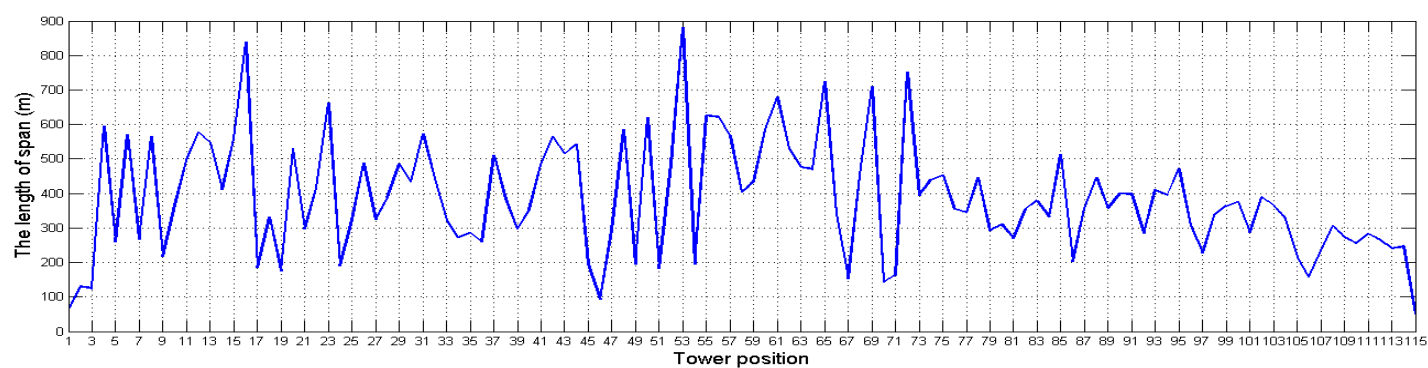

(b)

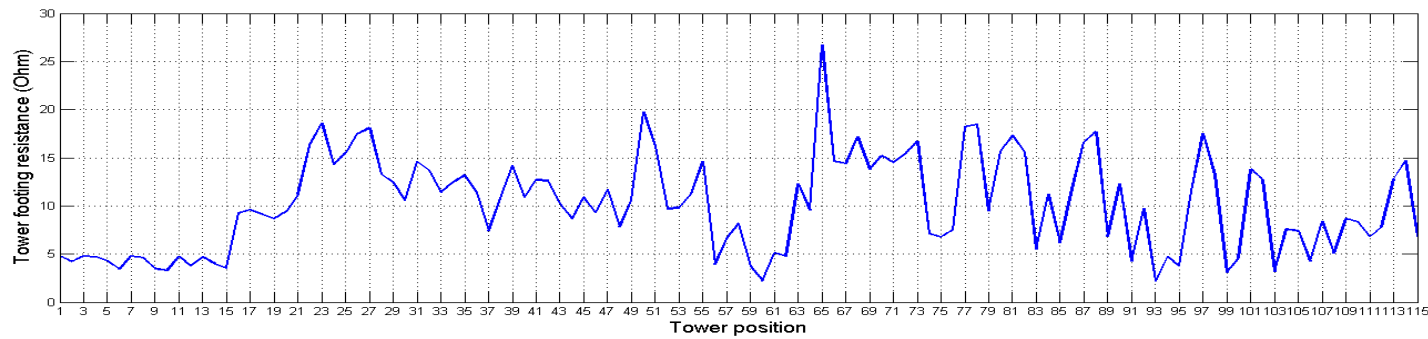

(c)

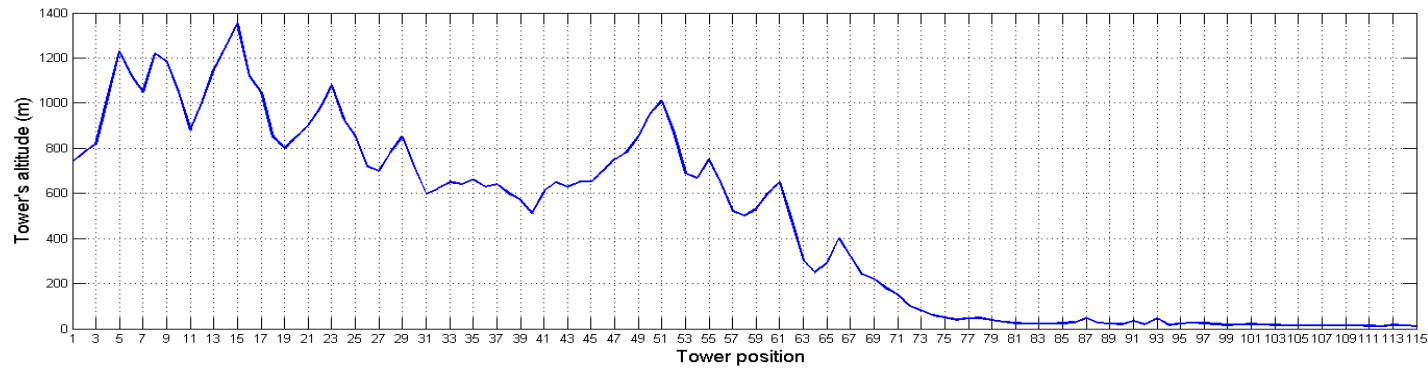

(d)

Figure 2. Some parameters: (a) the heigth of towers, (b) the length of span

(c) tower footing resistance at towers, (d) the altitude of towers 
With above parameters, the NFCL at towers is shown as the dotted curve in Figure 3(a). From this figure, it is easy to calculate the NFCL value in total of the line is 1.6365 flashes/year. Moreover, from this figure, it is clearly that the NFCL value is non-uniform at all towers on the line. Generally, the higher tower is, the higher NFCL is. Hence, to reduce the fault number, the tower with the highest NFCL value should be prioritized to improve.

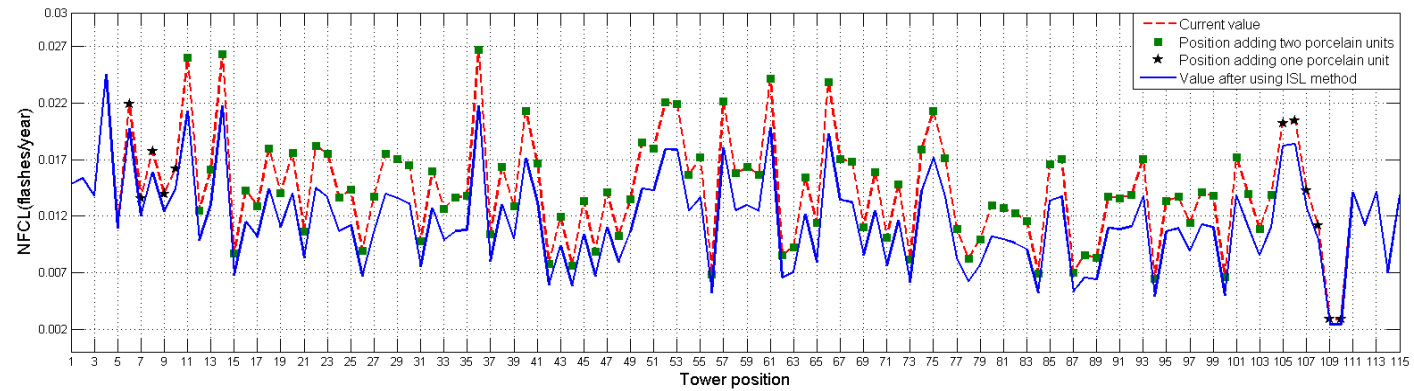

(a)

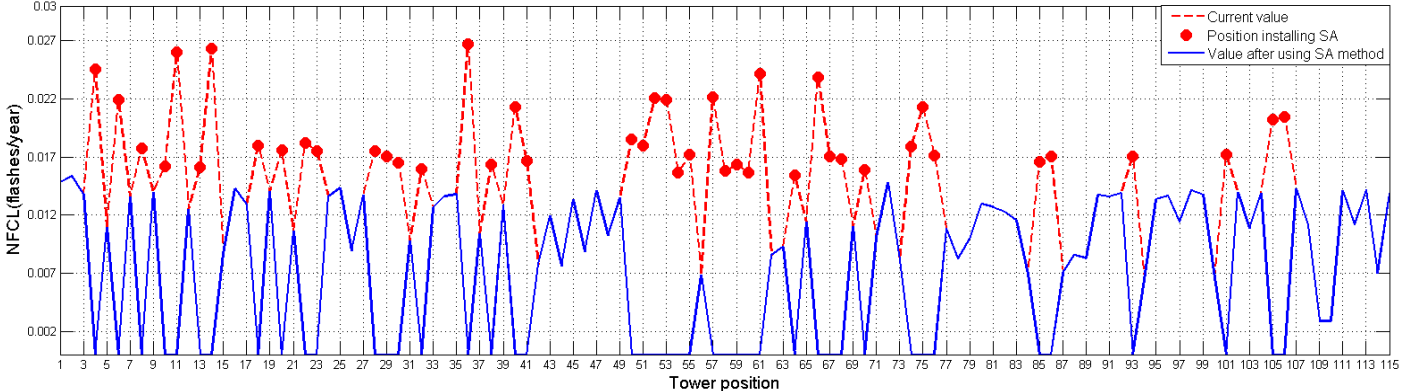

(b)

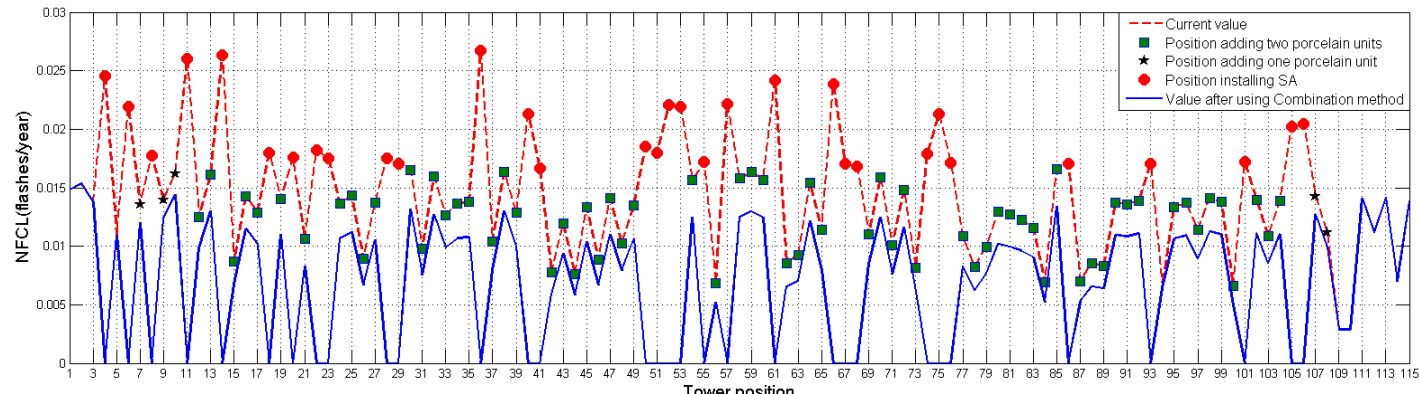

(c)

Figure 3. Calculation results: (a) ISL method, (b) SA method and (c) the combination method

We suppose that the average cost to install one SA at phase wires of a tower is $C_{S A}=8100 \mathrm{usd}$ and the average data to add one and two porcelain units at all strings of a tower are $C_{S 1}=158 \mathrm{usd}$ and $C_{S 2}=226 \mathrm{usd}$, respectively. It is noted that these costs include the price of SA or porcelain units, installation and compensation for power outage caused by adding SA or porcelain units into tower. We also suppose that we must reduce the total NFCL value to $50 \%$ of the current value, 1.6365 flashes/year. It means $n_{r e q}=0.8183$ flashes/year. To achieve this objective, the above algorithm is implemented and the best method which is suggested by this algorithm is the combination of SA and ISL. This algorithm also give us results as Table 1 and Figure 3.

Table 1 . The investment cost and the total NFCL value after using methods

\begin{tabular}{lccc}
\hline Indexes & ISL method & SA method & Combination method \\
\hline NFCL flashes/year & 1.3399 & 0.8069 & 0.8174 \\
Investment (usd) & 23279 & 356400 & 274906 \\
\hline
\end{tabular}


As can be seen from Table 1 and Figure 3, with the ISL method, although we added porcelain units at all permitted tower, the total NFCL value is still higher the requirement. Therefore, the ISL method is not considered. With the SA method, it can be seen that 44 towers in total should be installed SA and the NFCL value of these tower is very high. As a result, the total NFCL value is reduced to 0.8069 flashes/year which satisfies the requirement. In contrast, with the combination method, it requires to install SA at 32 tower positions, 66 tower positions with two porcelain units and 5 tower positions with one porcelain unit. As a results, the total NFCL value after using the combination method is reduced to 0.8174 flashes/year which is a lite higher than that using the SA method but it still satisfies the requirement. In terms of investment cost, the combination method's investment cost is lower than that of the SA method. The data are 274906usd and 356430 usd for the combination method and the SA method, respectively. Therefore, the combination method is recommended to improve this transmission line.

With this algorithm, we can estimate the method which should be used to improve the transmission line when the required fault number is changed. As can be see from Figure 4, with a small decrease in $n_{\text {req }}$, between 90 and $100 \%$ of the current NFCL value, the ISL method should be used because it can give a small investment. Out of this range, the ISL method cannot be applied because the NFCL vaule cannot satisfy the requirement. With this range, the combination method is still better than the SA method. With the combination method, the number of towers with SA installation, two porcelain units, and a porcelain unit is shown in Figure 4(c).

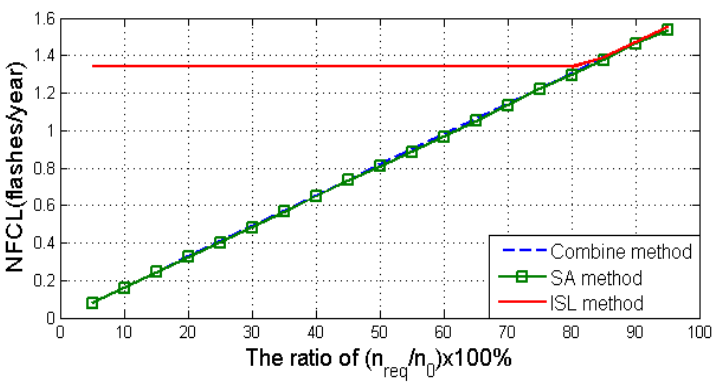

(a)

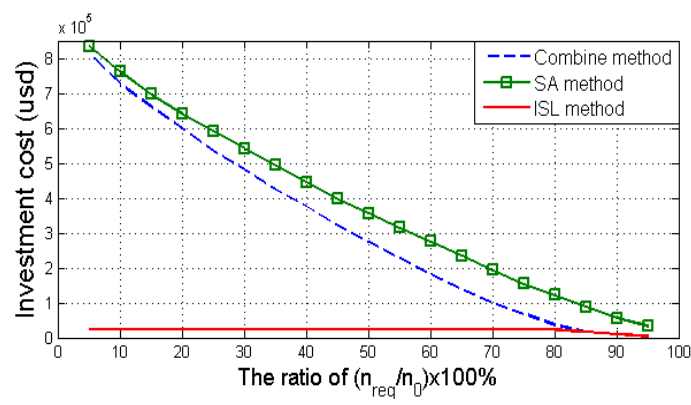

(b)

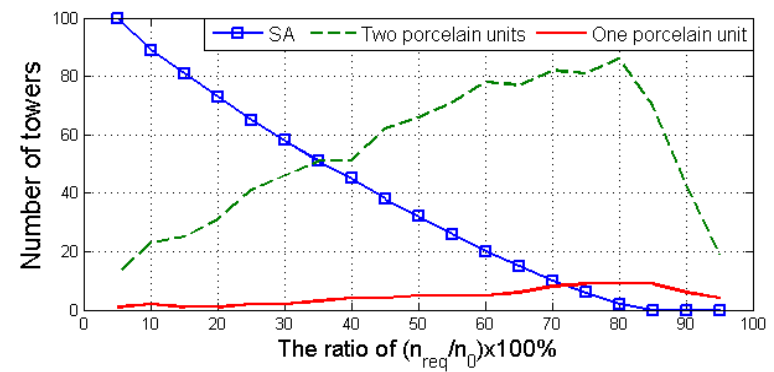

(c)

Figure 4. Calculation results as varying the required NFCL: (a) NFCL, (b) investment cost, and (c) number of towers needing to be improved

\section{CONCLUSION}

In this paper, author proposed an algorithm to determine method which is used to reduce the fault number caused by lightning on transmission line. The algorithm is developed based on three methods including increase in the insulator string length, surge arrestor installation, and combination of SA installation and increase in the insulator string length. Algorithm's output is the proposed method which can make the line's total NFCL value satisfy the requirement and give a reasonable investment cost. Based on this algorithm, the reasonable method (number position needing to improve) to reduce the fault number of transmission line can determine if we know the ratio of the required NFCL value and the current one. 


\section{REFERENCES}

[1] A. I. E. Gayar and Z. A. Malek, "AC interference on gas pipelines due to phase to ground faults in overhead transmission lines," International Journal of Electrical and Computer Engineering, vol/issue: 6(3), pp. 1363-1370, 2016.

[2] H. M. Luqman, et al., "Planning and conducting magnetic field level measurement from overhead transmission line," International Journal of Electrical and Computer Engineering, vol/issue: 7(6), pp. 3124-3132, 2017.

[3] A. I. E. Gayar and Z. A. Malek, "Induced voltages on a gas pipeline due to lightning strikes on nearby overhead transmission line," International Journal of Electrical and Computer Engineering, vol/issue: 6(2), pp. 495-503, 2016.

[4] A. O. Melodi and M. O. Oyeleye, "Modeling of lightning strike events, and it's correlational with power outages in south-west coast, Nigeria," International Journal of Electrical and Computer Engineering (IJECE), vol/issue: 8(7), pp. 3262-3270, 2017.

[5] O. E. S. Gouda and N. A. Elshesheny, "Simulation of the lightning back-flashover for medium voltage distribution network," Indonesian Journal of Electrical Engineering and Computer Science, vol/issue: 3(2), pp. 264-272, 2016.

[6] Z. Liu, "Ultra-high voltage AC/DC grids," Academic Press, Elsevier, UK, 2015.

[7] H. Zhou, et al., "Ultra-high voltage AC/DC power transmission," Springer, 2018.

[8] J. Geng, et al., "Calculation of lightning outage rate of high voltage transmission line," Asia-Pacific Power and Energy Engineering Conference, 2012.

[9] M. H. Shwehdi, et al., "Computing of lightning impulse back flashower outages rates on high voltage transmission lines," International journal of Automation and Power Engineering, vol/issue: 3(1), pp. 18-22, 2014.

[10] Zhou, et al., "A hybrid approach to calculate the shielding failure-caused trip-out rate," The International Seminar on Applied Physics, Optoelectronics and Photonics, 2016.

[11] A. R. Hileman, "Insulation coordination for power systems," CRC Press Taylor\& Francis Group, 6000 Broken Sound Parkway NW, Suite 300, 1999.

[12] A. H. A. Bakar, et al., "Lightning back flashover double circuit tripping pattern of $132 \mathrm{kV}$ Malaysia," International Journal of Electrical Power I\& Energy Systems, vol/issue: 45(1), pp. 235-241, 2013.

[13] F. Amanifard, et al., "Back-flashover investigation of HV transmission lines using transient modeling of the grounding systems," Iranian journal of Electrical \& Electronic Engineering, vol/issue: 12(3), pp. 222-229, 2016.

[14] A. S. Ghoniem, "Effective elimination factors to the generated lightning flashover in high voltage transmission network," International Journal on Electrical Engineering and Informatics, vol/issue: 9(3), pp. 455-468, 2017.

[15] T. Judendorfer, et al., "Line arrester application on a $110 \mathrm{kV}$ high alpine overhead line to reduce lightning-caused outages," Journal of Energy, vol. 60, pp. 81-87, 2011.

[16] N. Malcolm, et al., "An analysis of reducing back flashover faults with surge arresters on 69/138 kV double circuit transmission lines due to direct lightning strikes on the shield wires," In 12th IET International Conference on Developments in Power System Protection, pp. 1-6, 2014.

[17] H. Wang-jun, "Modeling and simulation research on lightning over-volatge of 500kV hydroelectric station," TELKOMNIKA Telecommunication Computing Electronics and Control, vol/issue: 10(4), pp. 619-624, 2012.

[18] L. Chunhua, et al., "Lightning performance and its prevention for quadruple-circuit transmission line with $220 \mathrm{kV} / 110 \mathrm{kV}$ Voltage in a Tower," TELKOMNIKA Telecommunication Computing Electronics and Control, vol/issue: 11(10), pp. 5833-5841, 2013.

\section{BIOGRAPHIES OF AUTHORS}

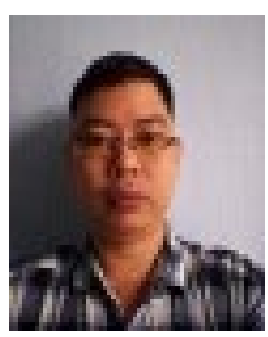

Dinh Chung Phan is a lecturer at The University of Danang-University of Science and Technology. He obtained Master degree from Dongguk University-Korea in 2011 and $\mathrm{PhD}$ degree from Kanazawa University-Japan in 2017. His researches are in fields of renewable energy, the control of power system, high voltage engineering. Further info on his homepage:

http://scv.udn.vn/phandinhchung 